\title{
Severe Sepsis in the Emergency Department - An Observational Cohort Study from the University Hospital of the West Indies
}

\author{
R Edwards ${ }^{1}$, R Hutson ${ }^{1}$, J Johnson ${ }^{1}$, R Sherwin ${ }^{2}$, G Gordon-Strachan³ ${ }^{3}$ M Frankson ${ }^{3}$, P Levy², 4
}

\begin{abstract}
Objective: To describe the incidence, treatment and outcomes of patients with severe sepsis and septic shock in a setting where early goal directed therapy (EGDT) is not routinely performed.

Method: An observational study of all adult patients admitted from the emergency department (ED) of the University Hospital of the West Indies (UHWI) with a diagnosis of severe sepsis and septic shock from July 5, 2007 to September 1, 2008 was conducted. Baseline parameters, treatment patterns and inhospital outcomes were evaluated.

Results: A total of 58011 patients were seen and 762 (1.3\%) had sepsis, 117 (15.4\%) of whom were classified as severe sepsis or septic shock. Mean (SD) age was 59.2 (23.3) years and $49 \%$ were female. Medical history included hypertension (29\%), diabetes mellitus (26\%), stroke (8\%), heart failure (6\%) and HIV (6\%). The most common sources of sepsis were pneumonia (67\%) and urinary tract infection $(46 \%)$. Median, interquartile range (IQR) time from triage to antibiotic administration was 126 (88, 220) minutes and antibiotics were given to $65.7 \%$ within three hours. Overall, organisms were sensitive to empirical antibiotics in $69 \%$. Median (IQR) lactate was $5.3(4.5,7.5) \mathrm{mmol} / \mathrm{L}$. Most patients $(95 \%)$ were admitted to the ward; $1 \%$ went to the intensive care unit (ICU) and $2 \%$ died in the ED. Mean (SD) length of hospital stay was 9.5 (10.3) days. In-hospital mortality was $25 \%$ and survival correlated inversely with age $\left(r_{p b}=-0.25 ; \mathrm{p}=0.006\right)$.

Conclusion: Despite a lack of EGDT, sepsis treatment patterns were consistent with "best-practice" and mortality was lower than international comparators.
\end{abstract}

Keywords: Septic shock, severe sepsis

\section{Sepsis Severa en la Sala de Emergencias - Un Estudio Observacional de Cohorte en el Hospital Universitario de West Indies}

R Edwards ${ }^{1}$, R Hutson ${ }^{1}$, J Johnson ${ }^{1}$, R Sherwin ${ }^{2}$, G Gordon-Strachan ${ }^{3}$, M Frankson ${ }^{3}$, P Levy 2,4

\begin{abstract}
RESUMEN
Objetivo: Describir la incidencia, el tratamiento y los resultados para pacientes con sepsis severa y shock séptico en un entorno donde la terapia dirigida por metas tempranas (TDMT) no se realiza de modo rutinario.

Método: Se realizó un estudio observacional de todos los pacientes adultos con diagnóstico de sepsis severa y shock séptico, ingresados en la Sala de Emergencias del Hospital Universitario de West Indies (HUWI) desde el 5 de julio de 2007 al 1ero. de septiembre de 2008. Se evaluaron los parámetros iniciales de referencia, los patrones de tratamiento, y la evolución intrahospitalaria.

Resultados: Un total de 58011 pacientes fueron vistos, 762 (1.3\%) de ellos con sepsis. De estos casos con sepsis, 117 (15.4\%) fueron clasificados como sepsis severa o shock séptico. La edad media (SD) fue 59.2 (23.3) años y 49\% eran mujeres. Historia clínica incluía hipertensión (29\%), diabetes (26\%), accidente cerebrovascular (8\%), insuficiencia cardiaca (6\%) y VIH (6\%). Las fuentes más comunes de
\end{abstract}

From: ${ }^{1}$ Division of Emergency Medicine, Department of Surgery, Radiology, Anaesthesia and Intensive Care, The University of the West Indies, Kingston 7, Jamaica, ${ }^{2}$ Department of Emergency Medicine, Wayne State University School of Medicine, Michigan, USA. ${ }^{3}$ Health Research Resource Unit, Faculty of Medical Sciences, The University of the West Indies, Kingston 7 , Jamaica and ${ }^{4}$ Cardiovascular Research Institute, Wayne State University School of Medicine, Michigan, USA.
Correspondence: Dr R Edwards, Division of Emergency Medicine, Department of Surgery, Radiology, Anaesthesia and Intensive Care, The University of the West Indies, Kingston 7, Jamaica. E-mail: romayne. edwards@digicel.blackberry.com 
la sepsis fueron neumonía (67\%) e infección del tracto urinario (46\%). La mediana del tiempo (IQR) transcurrido desde la selección (triaje) hasta la administración de antibióticos fue $126(88,220)$ minutos, y los antibióticos fueron entregados al 65.7\% dentro de las tres horas. En general, los organismos fueron sensibles a los antibióticos empíricos en 69\%. La mediana del lactato (IQR) fue 5.3 $(4.5,7.5) \mathrm{mmol} / \mathrm{L}$. La mayoría de los pacientes (95\%) fueron ingresados a la sala; $1 \%$ se destinó a la unidad de cuidados intensivos (UCI), y el 2\% murió en la Sala de Emergencias. El promedio (SD) de la estancia hospitalaria fue de 9.5 (10.3) días. La mortalidad intrahospitalaria fue de 25\%, y la supervivencia se halló en correlación inversa con la edad ( $\left.r_{p b}=-.25 ; p=0.006\right)$.

Conclusión: A pesar de la falta de TDMT, los patrones del tratamiento de sepsis fueron consistentes con las "mejores prácticas", y la mortalidad fue menor comparada con los datos de comparación a nivel internacional.

Palabras clave: Shock séptico, sepsis grave

West Indian Med J 2013; 62 (3): 225

\section{INTRODUCTION}

Sepsis is defined as the presence or presumed presence of an infection accompanied by systemic manifestations of an inflammatory response (1). When severe, organ dysfunction is usually noted, with or without the presence of refractory hypotension (1-3). Severe sepsis and septic shock remain a leading cause of morbidity and mortality worldwide (4). Fatality rates of the sepsis syndrome range from 23 to $46 \%$, varying based on the phase of the continuum being evaluated (5-7). Approximately 751000 new cases of severe sepsis are diagnosed each year with about 500 deaths daily across the United States of America [USA] (4, 7, 8). Prolonged length of stay (LOS) is common, with the average patient requiring hospitalization for 19.6 days $(9,10)$. A similar disease burden has been reported in Europe and Australia with cumulative annual incidences ranging from 51 to 206 cases per 100 000 population $(9,10)$. In the USA, approximately $61 \%$ of all patients ultimately diagnosed with sepsis initially present to an Emergency Department (ED), with an annual estimated associated cost of US $\$ 16.7$ billion (1). While no national figures are available for Jamaica, anecdotal reports from the intensive care unit (ICU) at the University Hospital of the West Indies (UHWI) Kingston, Jamaica, suggest that sepsis accounts for a significant proportion of deaths among their admitted patient population.

With an improvement in life expectancy and further increases in the elderly population, the management of sepsis will continue to consume considerable healthcare resources, posing a major global health problem. The management of septic patients by ED physicians in the "golden hour" thus plays a pivotal role in their clinical outcome (11). This was clearly demonstrated by Rivers and colleagues, in their landmark evaluation of early goal directed therapy (EGDT) for severe sepsis (12). By aggressively responding to temporal changes in cardiac preload, afterload and contractility, and oxygen delivery/demand, these investigators were able to decrease absolute mortality by $16 \%$ and LOS by 3.8 days per patient (12).
Early goal directed therapy has since been identified as a vital component of the Surviving Sepsis Campaign (SSC), which is an international collaborative effort initiated by the Society of Critical Care Medicine, the European Society of Intensive Care Medicine and the International Sepsis Forum $(4,13,14)$. The mandate of the SSC is to decrease the overall mortality rate of sepsis by $25 \%$ in five years using evidence based guidelines and financing projects involved in the management of severe sepsis and septic shock. New breakthroughs in the treatment of the sepsis syndrome are therefore quite diverse and the SSC is urging governments, health agencies and doctors worldwide to adopt practices outlined in their guidelines (15). However, resource limitations may preclude the ability of some medical systems to implement what has emerged as the international standard of care (16).

While physicians practising in such resource-limited locations are likely to possess the acumen and requisite skills necessary for adherence to the SSC guidelines, availability of appropriate equipment poses a challenge. Development of treatment protocols that work within existing limitations, therefore, may help achieve mortality reduction goals of the SSC. To derive these protocols, however, comprehensive baseline data are needed. Thus while our ultimate goal is to identify components of EGDT which may be amenable to application in such a region where strict adherence to SSC guidelines may be unachievable, specific objectives of this study were to evaluate the incidence and outcomes of severe sepsis and septic shock and to ascertain information regarding relative practice patterns for sepsis management in a representative, resource-limited medical centre.

\section{SUBJECTS AND METHODS}

This is a prospective, observational study of patients with severe sepsis and septic shock who presented to the Emergency Medicine Division at the UHWI. The ED provides treatment for 53000 patients annually and admits 8000 to various services of the hospital.

Patients $>18$ years of age who met two or more systemic inflammatory response syndrome (SIRS) criteria [ie 
heart rate $(\mathrm{HR})>90$ beats/minutes, temperature $>38{ }^{\circ} \mathrm{C}$ or $<36{ }^{\circ} \mathrm{C}$, respiratory rate $(\mathrm{RR})>20$ breaths/minute, white blood cell (WBC) count $>12000$ or $<4000$ or $>10 \%$ bands, and baseline whole blood lactate concentration $\geq 4 \mathrm{mmol} / \mathrm{L}]$ and were diagnosed with sepsis, were eligible for study inclusion. Those with concurrent acute illness (ie cerebrovascular event, coronary syndrome, cardiogenic pulmonary oedema, status asthmaticus, primary dysrhythmia, seizure, drug overdose or major trauma) which necessitated diseasespecific intervention and those with active cancer, on immunosuppression or active 'do not resuscitate' orders were excluded.

Data were prospectively collected from eligible patients ("cases") between July 5, 2007 and September 1, 2008 using standardized data collection forms. To enable evaluation of potentially distinguishing characteristics of study cases, data for all sepsis patients treated in the ED at UHWI during the study period, and a group of adult patients (age $>18$ years) admitted for conditions other than sepsis ("controls") during a subsequent time period (August 1, 2009 to October 31, 2009) were prospectively compiled. Specific data of interest included baseline parameters, treatment and outcome measures. All data elements were readily available from existing records and no additional information was solicited. Consequently, this project did not interfere with patient care and waiver of informed consent was permitted by the University Hospital of the West Indies Ethics Committee.

Descriptive clinical, demographic and historical data for cases and controls, as well as the physician management patterns of the cases were analysed. Differences between cases and controls were compared using Student's $t$-test for nominal parametric data and the independent samples MannWhitney $U$ test of median differences for non-parametric data. Dichotomous bivariate data (eg presence of co-morbidities by group and gender) were compared utilizing the Chi-squared test of independence. Logistic regression analysis was conducted to assess the independent contribution of clinically relevant variables for pre-specified outcomes (ie in-hospital survival and hospital LOS stay). All data were analysed using SPSS version 12.0.

\section{RESULTS}

Over the study period, a total of 58011 patients were seen in the ED at the UHWI, $762(1.3 \%)$ of whom were diagnosed as having sepsis. Of the sepsis group, 117 (15.4\%) were diagnosed with severe sepsis $(n=113)$ and septic shock $(n=4)$. The mean (SD) age of these patients (Table 1) was 59.2

Table 1: Baseline characteristics of patients presenting with severe sepsis

\begin{tabular}{ll}
\hline $\begin{array}{l}\text { Variable } \\
\text { Mean (SD) age in years* }\end{array}$ & $\begin{array}{l}\text { Severe sepsis patients } \\
(\mathbf{n}=\mathbf{1 1 7})\end{array}$ \\
\hline Overall & $59.2(23.3)$ \\
Female & $61.3(21.3)$ \\
Male & $56.9(25.3)$ \\
Sex (\%)* & \\
Female & 49 \\
Male & 51 \\
Chronic medical conditions (\%) & \\
Congestive heart failure & 6 \\
Chronic obstructive pulmonary disease & 3 \\
Sickle cell disease & 3 \\
Diabetes mellitus & 26 \\
Hypertension & 29 \\
Human immunodeficiency virus & 6 \\
Liver disease & 1 \\
Kidney disease & 4 \\
History of cancer & 4 \\
History of cerebrovascular accidents & 8 \\
Renal disease & 4 \\
Dementia & 3
\end{tabular}

* Because two patients were enrolled twice, $\mathrm{n}$ for these variables $=115$

(23.3) years with a predilection toward inclusion of older females compared to males (61.3 (21.2) vs 56.9 (25.3) years). Hypertension (29\%) and diabetes (26\%) were the most common co-morbidities, followed by cerebrovascular accidents $(8 \%)$, heart failure $(6 \%)$ and human immunodeficiency virus $(6 \%)$. The prevalence of such co-morbidities was generally similar to the group of control patients $(n=1243)$, where hypertension was present in $24 \%$, diabetes mellitus in $14 \%$, cerebrovascular accidents in $4 \%$, heart failure in $5 \%$ and human immunodeficiency virus in $1 \%$.

Baseline SIRS criteria data are shown in Table 2 and time-dependent data are shown in Table 3. Mean (SD) sys-

Table 2: Distribution of the systemic inflammatory response syndrome criteria

\begin{tabular}{lccccccc}
\hline $\mathbf{n}=$ & $\mathbf{1 1 7}$ & $\mathbf{1 1 7}$ & $\mathbf{1 1 7}$ & $\mathbf{1 1 7}$ & $\mathbf{2 9}$ & $\mathbf{1 1 6}$ & $\mathbf{1 1 7}$ \\
\hline Variable & Temp $\left({ }^{\circ} \mathrm{F}\right)$ & $\begin{array}{c}\text { Heart rate } \\
\text { beats/min }\end{array}$ & $\begin{array}{c}\text { Respiratory } \\
\text { rate }\end{array}$ & $\begin{array}{c}\text { Systolic } \\
\text { blood pressure } \\
(\mathrm{mmHg})\end{array}$ & $\begin{array}{c}\text { Partial pressure } \\
\text { carbon dioxide } \\
(\mathrm{mmHg})\end{array}$ & $\begin{array}{c}\text { White cell } \\
\text { count } \\
\left(\text { per } \mathrm{mm}^{3}\right)\end{array}$ & Lactate \\
Mean & 100.04 & 116.49 & 33.13 & 119.62 & 28.59 & 13.67 & 6.61 \\
(SD) & \pm 2.76 & \pm 24.70 & \pm 10.77 & \pm 29.65 & \pm 9.98 & \pm 8.82 & \pm 3.36 \\
Median & 100.40 & 115.00 & 28.00 & 116.00 & 26.00 & 11.30 & 5.30 \\
IQR & $97.85-102.35$ & $102.00-134.00$ & $24.00-40.00$ & $96.50-137.00$ & $22.50-31.50$ & $7.83-17.27$ & $4.50-7.50$ \\
\hline
\end{tabular}


Table 3: Time-dependent treatment parameters

\begin{tabular}{|c|c|}
\hline \multicolumn{2}{|c|}{ Time from triage to enrolment (minutes) } \\
\hline Mean & $67.69 \pm 59.53(\mathrm{n}=110)$ \\
\hline *entiles: $25^{\text {th }}$ & 23.75 \\
\hline * $\quad 50^{\text {th }}$ & 55.00 \\
\hline $75^{\text {th }}$ & 95.00 \\
\hline Minimum time (minutes) & 0 \\
\hline Maximum time (minutes) & 305 \\
\hline \multicolumn{2}{|c|}{ Time from enrolment to referral to specialist (minutes) $(n=88)$} \\
\hline Mean & $173 \pm 143.64(n=88)$ \\
\hline *entiles: $25^{\text {th }}$ & 83.25 \\
\hline * $\quad 50^{\text {th }}$ & 130 \\
\hline $75^{\text {th }}$ & 217 \\
\hline Minimum and maximum time & 20 and 905 \\
\hline \multicolumn{2}{|c|}{ Time from enrolment to antibiotic administration (minutes) $(n=99)$} \\
\hline Mean & $165 \pm 111.3$ \\
\hline *entiles: $25^{\text {th }}$ & 88.00 \\
\hline * $\quad 50^{\text {th }}$ & 126.00 \\
\hline $75^{\text {th }}$ & 220.00 \\
\hline Minimum time & 15 \\
\hline Maximum time & 536 \\
\hline \multicolumn{2}{|c|}{ Centiles $\left(25^{\text {th }}-88 ; 50^{\text {th }}-126 ; 75^{\text {th }}-220\right)$} \\
\hline \multicolumn{2}{|l|}{ Antibiotic therapy } \\
\hline Within the first two hours & $47.5 \%$ \\
\hline Within the first three hours & $65.7 \%$ \\
\hline Within the first four hours & $78.8 \%$ \\
\hline Within the first six hours & $93 \%$ \\
\hline Within the first eight hours & $100 \%$ \\
\hline
\end{tabular}

tolic blood pressure was 119.6 (29.7) $\mathrm{mm} \mathrm{Hg}$ and mean (SD) serum lactate was $6.6(3.4) \mathrm{mmol} / \mathrm{L}$. Mean (SD) time from triage to enrolment was 67.7 (59.5) minutes and empirical antibiotics were administered to $47.5 \%$ of the study group within two hours of being seen by the physician. Within three hours, $65.7 \%$ of the patients had received antibiotics and all were treated within eight hours. This distribution was skewed by three of the patients who were given antibiotics at 7, 7.5 and 8.9 hours after arrival to the ED. Cultures from suspected sources of infection were taken for all study patients, with the lung and urinary tract serving as the most common location (Figure). As shown in Table 4, there were almost equal percentages of culture negative and positive results at $49 \%$ and $47 \%$, respectively. Gram negative organisms accounted for $54 \%$ of the positive blood cultures and
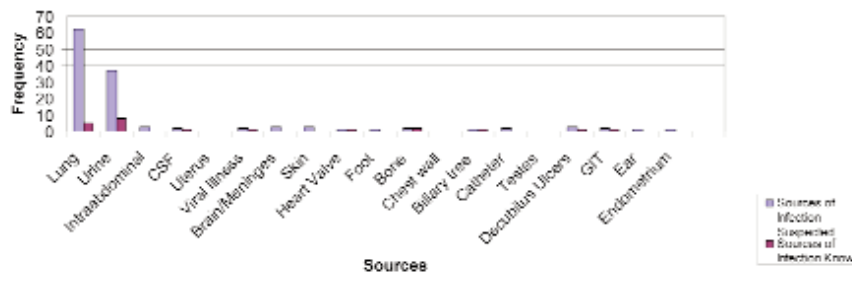

Figure: Suspected and known sources of infection.
Table 4: Culture results

\begin{tabular}{|c|c|}
\hline Total & $\mathrm{n}=117(\%)$ \\
\hline Culture negative & $57(49)$ \\
\hline Culture positive & $55(47)$ \\
\hline Missing data (no blood/urine found) & $5(4)$ \\
\hline Blood culture positive & $16(29)$ \\
\hline Urine culture positive & $17(31)$ \\
\hline Blood and urine positive & $17(31)$ \\
\hline Unknown & $3(5)$ \\
\hline Other (wound) & $2(4)$ \\
\hline Bloo & \\
\hline GNB & $18(54)$ \\
\hline GPC & $14(42)$ \\
\hline \multirow[t]{2}{*}{ GNB and GPC } & $1(4)$ \\
\hline & \\
\hline GNB & $26(76)$ \\
\hline GPC & $6(18)$ \\
\hline Yeast & $2(6)$ \\
\hline
\end{tabular}

GNB-gram negative bacilli; GPC-gram positive cocci

$76 \%$ urine cultures. Co-amoxiclavulanic acid (48\%), ceftriaxone $(26 \%)$ and ceftazidime (16\%) were the most frequently used empirical antibiotics (Table 5) and the organism was sensitive to the initial antibiotic choice in $69 \%$ of the study population.

\begin{tabular}{lc} 
Table 5: Empiric antibiotics and sensitivity patterns \\
\hline Sensitivity of empirical antibiotics \\
\hline Sensitive (blood and urine) & $38 / 55=69 \%$ \\
Resistant & $3 / 55=5 \%$ \\
Unknown & $26 \%$ \\
Empirical antibiotics given & $\mathbf{n}(\mathbf{\%})$ \\
Amoxillin/clavulanic acid & $58(48)$ \\
Clindamycin & $1(0.8)$ \\
Metronidazole & $8(6.6)$ \\
Ceftriaxone & $31(26)$ \\
Ceftazidime & $19(16)$ \\
Cloxacillin & $1(0.8)$ \\
Norfloxacin & $1(0.8)$ \\
Cefuroxime & $2(0.8)$ \\
Gentamicin & $2(0.8)$ \\
\hline
\end{tabular}

Seventy-eight per cent of all the referrals were made to the medical service, $15 \%$ to the urology service and $7 \%$ to the surgical team. One central venous pressure line was inserted in the ED and no patient received a blood transfusion. Nearly all patients $(95 \% ; \mathrm{n}=112)$ were admitted to hospital, only one of whom went to the ICU. Four patients $(3 \%)$ with severe sepsis were discharged home and two patients died in the ED. Mean (SD) hospital LOS was 9.5 (10.3) days and 29 patients $(25 \%)$ died in-hospital. There was a statistically significant $(p=0.006)$ association between age and mortality rate, with a point biserial correlation coefficient $\left(\mathrm{r}_{\mathrm{pb}}\right)=-0.25$ and a coefficient of determination $\left(\mathrm{r}^{2} \mathrm{pb}\right)=0.063$. Although there was a significant difference in median LOS for the patients who survived versus those who died ( 8 vs 2 days; $p$ $=0.007)$, there was no statistical association between LOS 
and mortality on adjusted models (OR 1.040; 95\% CI: 0.924 , $1.169)$. Of the 88 patients who were discharged, only $1(1 \%)$ required nursing home place-ment.

\section{DISCUSSION}

In this first survey of severe sepsis and septic shock among individuals who reside in the Caribbean, several findings were noteworthy. Firstly, despite an overwhelming lack of resources, major time-sensitive metrics showed an ability to approximate best practices employed in the USA and Europe $(1,4,12)$. Of particular note, the median time from triage to antibiotics was 126 minutes and by three hours, nearly twothirds of the patients had received antibiotic therapy. We were unable to achieve $100 \%$ compliance with current recommendations that require the administration of empirical broad-spectrum antibiotics within three hours of ED arrival; however, the compliance rate can be improved if enhanced surveillance of potential cases and systems-based approaches to improve sepsis care are implemented (17).

Secondly, the organisms isolated in this study were predominantly gram-negative bacilli (GNB) in both blood and urine cultures (54\% and $76 \%$, respectively). This contrasts the pattern of isolates in the USA, where gram-positive organisms standout as the predominant pathogens in severe sepsis and septic shock (18). This may reflect the relative frequency of a known or suspected urinary source of infection in our study cohort. A higher prevalence of gramnegative sepsis has previously been reported at UHWI and this apparent propensity should be considered when empirical antibiotics are selected for patients with suspected sepsis (19). Survival is improved when such antibiotic coverage has in vitro activity against the pathogenic bacteria and, to increase the likelihood of this occurring, combination antimicrobial therapy has been advocated (1). In this study, amoxicillin/clavulanic acid, ceftriaxone and ceftazidime were used most often, typically in combination with metronidazole, clindamycin or gentamicin. As a result, $69 \%$ of bacteria culture isolates were sensitive to empirical antibiotics administered.

Thirdly, consistent with prior studies of severe sepsis, older individuals were over-represented in the study population $(7,12,20-22)$. This age-related prevalence has been attributed to a progressive immune dysfunction that accompanies ageing, where a failure of leukocytes to process antigens and an alteration in inflammatory cytokine expression ensues (23-28). The elderly are also more likely to contract diseases with a propensity to induce sepsis such as pneumonia or urinary tract infections (29-33). Other risk factors include the presence of co-morbidities (especially conditions such as dementia and immobility), instrumentation and institutionalization $(17,20)$. As with other studies, we also found an association between age and mortality $(20,21)$. However, when adjusting for other clinical factors, age was found to explain only $6.3 \%$ of the variance in in-hospital death.
Fourthly, whilst $95 \%$ were admitted to hospital, only one patient was sent to the ICU. At UHWI, access to the ICU is limited by bed and critical care staff availability and admissions are generally restricted to patients who are extremely ill. Whether such management decision-making was influenced by an over-reliance on con-ventional (and imperfect) measures of haemodynamic status and how it may have impacted patient outcomes, is not known; however, admission of patients with severe sepsis (especially when septic shock is present) to a non-monitored setting is clearly suboptimal. This is reflected by the fact that, despite inclusion of a seemingly lower risk cohort (ie only 3\% had diagnosed septic shock), our in-hospital mortality rate was $25 \%$. This is $5 \%$ less than the standard therapy group in the seminal paper on EDGT by Rivers and colleagues, but their study included a far sicker population with septic shock in nearly $51 \%$. While mortality rate may have been lower, if a greater proportion of patients had been admitted to the ICU where principles of EGDT such as aggressive fluid resuscitation (to include blood products), the use of invasive monitoring and early ventilatory support could have been utilized, fatality rates may have been significantly reduced.

That only $3 \%$ of the included cohort met criteria for septic shock is in fact a limitation of this study. Such a finding is inconsistent with other sepsis studies, where the prevalence of septic shock is usually closer to $50 \%$. There are several factors that may account for the high proportion of severe sepsis (versus septic shock) noted in the present study. Indeed, it may be truly reflective of a relatively low severity of sepsis presentations to the ED at UHWI. Alternatively, it may reflect the method of enrolment in the study, where it was necessary to have a point of care lactate (used as an objective criterion of severe sepsis) before intervention was initiated to achieve entry into the study. Those patients who presented with hypotension, in addition to other features of sepsis, may have been more likely to receive immediate fluid resuscitation before lactate measurement could be performed thus precluding them from study inclusion. Regrettably, research assistants were not available to enlist such patients or document the numbers that may have been excluded and these data were not forthcoming after a retrospective review of the records. An additional finding is the relatively high proportion of negative yield cultures. This may reflect the unique microbial patterns in this population. Further research would be required to detail the various causes of the numbers of negative cultures.

In summary, this study suggests that current care in the ED at the UHWI for sepsis when compared to landmark studies of EGDT and the SSC may be similar with respect to time to physician treatment, timing of antibiotic treatment, hospital LOS, and mortality rate. Improvements in outcome, however, may be achievable with implementation of EGDT and SSC principles and based on our results, further exploration of such a possibility is warranted. 


\section{REFERENCES}

1. Nguyen HB, Rivers EP, Abrahamian FM. Severe sepsis and septic shock: review of the literature and emergency department management guidelines. Ann Emerg Med 2006; 48: 28-54.

2. Levy MM, Fink MP, Marshall JC. International sepsis definitions conference. Crit Care Med 2003; 31: 1250-6.

3. Marshall JC, Cook DJ, Christou NV, Bernard GR, Sprung CL, Sibbald WJ. Multiple organ dysfunction score: a reliable descriptor of a complex clinical outcome. Crit Care Med 1995; 23: 1638-52.

4. Osborn TM, Nguyen HB, Rivers EP. Emergency medicine and the surviving sepsis campaign: an international approach to managing severe sepsis and septic shock. Ann Emerg Med 2005; 46: 228-31.

5. Dellinger RP. Cardiovascular management of septic shock. Crit Care Med 2003; 31: 946-55.

6. Osborn TM, Tracy JK, Dunne JR, Pasquale M, Napolitano LM. Epidemiology of sepsis in patients with traumatic injury. Crit Care Med 2004; 32: 2234-40.

7. Angus DC, Linde-Zwirble WT, Lidicker J, Clermont G, Carcillo J, Pinsky MR. Epidemiology of severe sepsis in the United States: analysis of incidence, outcome, and associated costs of care. Crit Care Med 2001; 29: 1303-10.

8. Watson RS, Carcillo JA, Linde-Zwirble WT, Clermont G, Lidicker J, Angus DC. The epidemiology of severe sepsis in children in the United States. Am J Respir Crit Care Med 2003; 167: 695-701.

9. Brun-Buisson C, Meshaka P, Pinton P, Vallet B; EPISEPSIS Study Group. EPISEPSIS: a reappraisal of the epidemiology and outcome of severe sepsis in French intensive care units. Intensive Care Med 2004; 30: $580-8$.

10. Finfer S, Bellomo R, Lipman J, French C, Dobb G, Myburgh J. Adultpopulation incidence of severe sepsis in Australian and New Zealand intensive care units. Intensive Care Med 2004; 30: 589-96.

11. Blow O, Magliore L, Claridge JA, Butler K, Young JS. The golden hour and the silver day: detection and correction of occult hypoperfusion within 24 hours improves outcome from major trauma. J Trauma 1999; 47: $964-9$

12. Rivers EP, Nguyen HB, Havstad S. Early goal-directed therapy in the treatment of severe sepsis and septic shock. N Engl J Med 2001; 345: 1368-77.

13. Hollenberg SM, Ahrens TS, Annane D, Astiz ME, Chalfin DB, Dasta JF et al. Practice parameters for haemodynamic support of sepsis in adult patients: 2004 update. Crit Care Med 2004; 32: 1928-48.

14. Practice parameters for haemodynamic support of sepsis in adult patients in sepsis. Task Force of the American College of Critical Care Medicine, Society of Critical Care Medicine. Crit Care Med 1999; 27: 639-60.

15. New international guidelines support early goal directed therapy to treat sepsis. Edwards Lifesciences Corporation; 2005 [Cited July 20, 2006]. Available from: http://www.biospace.com/news_story.aspx? NewsEntityId $=15274520$

16. Wood K, Angus D. Pharmacoeconomic implications of new therapies in sepsis. PharmacoEconomics 2004; 22: 895-906.
17. Girard T, Ely E. Bacteremia and sepsis in older adults. Clin Geriatr Med 2007; 23: 633-47.

18. Martin GS, Mannino DM, Eaton S. The epidemiology of sepsis in the United States from 1979 through 2000. N Engl J Med 2003; 348: $1546-54$

19. Bodonaik N, Brown R, Nicholson A. Pattern of isolates of bloodstream infections at the UHWI: comparison with those observed in other developing and developed countries. (unpublished data)

20. Martin G, Mannino D, Moss M. The effect of age on the development and outcome of adult sepsis. Crit Care Med 2006; 34: 15-21.

21. Brun-Buisson C, Doyon F, Carlet J. Bacteremia and severe sepsis in adults: a multicenter prospective survey in ICUs and wards of 24 hospitals. French Bacteremia-Sepsis Study Group. Am J Respir Crit Care Med 1996; 154: 617-24.

22. Baine WB, Yu W, Summe JP. The epidemiology of hospitalization of elderly Americans for septicemia or bacteremia in 1991-1998: Application of Medicare claims data. Ann Epidemiol 2001; 11: $118-26$.

23. Turnbull IR, Wlzorek JJ, Osborne D. Effects of age on mortality and antibiotic efficacy in cecal ligation and puncture. Shock 2003; 19: $310-13$

24. Pawelec G, Solana R, Remarque E. Impact of ageing on innate immunity. J Leukoc Biol 1998; 64: 703-12.

25. Tateda K, Matsumoto T, Miyazaki S. Lipopolysaccharide-induced lethality and cytokine production in aged mice. Infect Immun 1996; 64: 769-74.

26. Bruunsgaard H, Skinhoj P, Qvist J. Elderly humans show prolonged in vivo inflammatory activity during pneumococcal infections. J Infect Dis 1999; 180: 551-4.

27. Gabriel P, Cakman I, Rink L. Overproduction of monokines by leukocytes after stimulation with lipopolysaccharide in the elderly. Exp Gerontol 2002; 37: 235-47.

28. Yamamoto K, Shimokawa T, Yi H. Ageing accelerates endotoxininduced thrombosis: increased responses of plasminogen activator inhibitor-1 and lipopolysaccharide signaling with ageing. Am J Pathol 2002; 161: 1805-14.

29. Wheeler AP, Bernard GR. Treating patients with severe sepsis. N Engl J Med 1999; 340: 207-14.

30. Tran DD, Groeneveld AB, van der MJ. Age, chronic disease, sepsis, organ system failure, and mortality in a medical intensive care unit. Crit Care Med 1990; 18: 474-9.

31. Knaus WA, Wagner DP, Draper EA. The APACHE III prognostic system. Risk prediction of hospital mortality for critically ill hospitalized adults. Chest 1991; 100: 1619-36.

32. Pittet D, Thievent B, Wenzel RP. Importance of pre-existing comorbidities for prognosis of septicemia in critically ill patients. Intensive Care Med 1993; 19: 265-72.

33. Walter LC, Brand RJ, Counsell SR. Development and validation of a prognostic index for 1-year mortality in older adults after hospitalization. JAMA 2001; 285: 2987-94. 